\title{
Educação a Distância e o uso dos Ambientes Virtuais de Aprendizagem: entre o Ideal e o Possível
}

\author{
Distance Education and the use of the Virtual Learning \\ Environment: between the Ideal and the Possible
}

Educación a Distancia y uso de Ambientes Virtuales

de Aprendizaje: entre lo ideal y lo posible

AlesSANDRA MAIESKI

KÁTIA Morosov Alonso (Db

\section{Resumo}

É indiscutível a relevância dos Ambientes Virtuais de Aprendizagem (AVA) como espaços de formação, devido a consolidarem "lugares/espaços" de outras e novas apropriações das práticas pedagógicas. Justamente por isso a importância de pesquisas, discussões e problematizações voltadas para os processos formativos online, assim como para o uso dos AVA. Nesse artigo, quando se fala de mediação e de interação é em uma perspectiva histórico-cultural, compreendendo que esses conceitos se configuram como elementos promotores da aprendizagem, determinando as relações e os papéis dos sujeitos nos cursos de formação on-line. Nesse sentido, esse artigo apresenta parte dos resultados de uma pesquisa de Mestrado que tem como objetivo investigar os processos e procedimentos de mediação e de interação nos cursos de formação on-line da Universidade Federal de Mato Grosso (UFMT). Para responder a tal objetivo, o problema que se propôs investigar é como os processos e procedimentos de mediação e de interação podem ser identificados nos cursos de formação on-line da UFMT? A abordagem utilizada foi qualitativa, com a metodologia da observação participante. Os resultados apontam que se faz necessária uma discussão sobre políticas públicas e institucionais, sobre o trabalho docente e do tutor, e, no caso da EaD, sobre o "lugar" do aluno no contexto da cultura digital e da sociedade conectada.

\footnotetext{
a Universidade Federal de Mato Grosso, Cuiabá, MT, Brasil. Mestra em Educação, e-mail: alemaieski86@gmail.com

b Universidade Federal de Mato Grosso, Cuiabá, MT, Brasil. Doutora em Educação, e-mail: katia.ufmt@gmail.com
} 
Palavras-chave: Ambientes Virtuais de Aprendizagem. Formação On-line. Mediação. Interação.

\begin{abstract}
The Virtual Learning Environment (VLE) is extremely relevant as a development space, due to promoting "places/spaces" for other and new appropriation for pedagogical practices. Thus, mainly because of that, there is great importance in research projects, discussions and problematizations about online development processes, as well as in the VLE use. In this dissertation, mediation and the interaction are discussed from a historic and social perspective, understanding that these concepts set themselves as elements that promote learning, determining the subject's relations and roles in on-line majors. It presents part of the results of a research and aims at investigating the mediation and the interaction processes and procedures in the on-line training courses at University Federal de Mato Grosso (UFMT) To answer this objective, the problem you set out to investigate is how can mediation and the interaction processes and procedures be identified in the on-line training courses of the UFMT? Qualitative approach, with participant observation methodology were used. The results indicate the need to discuss public and institutional policies, about the work of teachers and tutors and, in the case of Distance Education, about the student's "place" in the context of digital culture and connected Society.
\end{abstract}

Keywords: Virtual Learning Environment. Online Training. Mediation. Interaction.

\title{
Resumen
}

La relevancia de los Ambientes Virtuales de Aprendizaje (AVA) como espacios de formación es indiscutible, debido a la consolidación de los "lugares / espacios" del otro y las nuevas apropiaciones de las prácticas pedagógicas. Precisamente por ello, la importancia de la investigación, las discusiones y la problematización relacionadas con los procesos de formación online, así como el uso de VLE. En este artículo, cuando se trata de mediación e interacción, es desde una perspectiva histórico-cultural, entendiendo que estos conceptos se configuran como elementos que promueven el aprendizaje, determinando las relaciones y roles de los sujetos en los cursos de formación online. El artículo presenta parte de los resultados de una investigación y tiene como objetivo investigar los procesos y procedimientos de mediación e interacción en los cursos de formación on-line de la Universidad Federal de Mato Grosso (UFMT). para dar respuesta a este objetivo, el problema que se propuso investigar es ccómo se pueden identificar los procesos y procedimientos de mediación e interacción en los cursos de formación online de UFMT? El enfoque utilizado fue cualitativo, con la metodología de observación participante. Los resultados muestran que es necesario discutir las políticas públicas e institucionales, el trabajo de docentes y tutores y, en el caso de la educación a distancia, sobre el "/ugar" del estudiante en el contexto de la cultura digital y la sociedad conectada.

Palabras clave: Ambientes virtuales de aprendizaje. Formación on-line. Mediación. Interacción. 


\section{Introdução}

A possibilidade de comunicação e de trocas em tempo real, sem os sujeitos estarem presentes no mesmo espaço e tempo, proporcionou transformações nos processos formativos por meio do uso das Tecnologias da Informação e Comunicação (TIC) (KERCKHOVE, 2009). Com as emergentes possibilidades que as TIC engendram aos processos formativos, presenciou-se, nos últimos anos, uma vertiginosa expansão da oferta de formação por meio da Educação a Distância (EaD), (ALONSO; SILVA, 2018) e isso "acarreta o advento de novos modos de compreender, de estudar, de ensinar e de acompanhar pedagogicamente a construção de conhecimentos" (SILVA, 2015, p. 19).

Diante desse cenário de mudanças e transformações no âmbito educacional, teve-se, por consequência, o uso mais intenso dos Ambientes Virtuais de Aprendizagem (AVA) como espaços de formação (MAIESKI; SILVA, 2021). Nesse sentido, também houve a insurgência desses Ambientes como espaços possibilitadores de práticas didático-pedagógicas pautadas em mediação e em interação.

A teoria sócio-histórica, com base em Vigotski, pressupõe que os processos de interação e mediação são fundamentais para as aprendizagens, atribuindo à cultura e à história papel de relevo nos processos do aprender vividos pelos humanos. A produção do conhecimento ocorreria, assim, por meio da interação do sujeito com o meio e com outros indivíduos em processos mediados. Essa produção seria, portanto, "profundamente social, enfatizando o diálogo e as diversas funções da linguagem na instrução e no desenvolvimento cognitivo mediado" (VIGOTSKI, 2007, p. 164). Para esse teórico, o professor é um mediador entre aquele que aprende (sujeito) e o mundo, apoiando-o a interagir com os outros e consigo mesmo. Nos processos educativos formais, incluindo a $\mathrm{EaD}$, isso não é diferente. Com o advento da cultura digital, a qual inclui crescentemente a comunicação mediada por meio das TIC, os AVA acabaram por constituir espaços de formação, pelo menos até o momento, possibilitadores de interação e mediação entre professores e alunos, como sujeitos do processo de ensino/aprendizagem. 
Nesse sentido, é indiscutível a relevância dos AVA como espaços de formação, devido a sustentarem "lugares" de outras e novas apropriações das práticas pedagógicas. Ampliar, portanto, o horizonte das pesquisas diante das possibilidades dos AVA nos processos educativos é, sem dúvida, um passo importante para que se possa reconhecer e compreender o que seria a formação com as TIC. Essa formação inclui também os AVA no contexto da cultura digital, porque esses manifestam uma formação com uso mais intenso de tecnologias.

Ao se compreender a importância de pesquisas, discussões e problematizações voltadas para os processos formativos na EaD, assim como para o uso dos AVA, apresenta-se neste artigo parte dos resultados de uma pesquisa realizada no Programa de Pós-Graduação em Educação, na UFMT, no âmbito do grupo de pesquisa LêTECE ${ }^{1}$. É importante ressaltar que o que está sendo expresso aqui é parte de várias pesquisas em andamento, cujo objetivo maior é o de, justamente, permitir reflexões sobre o uso das TIC em diferentes contextos do escolar, desde a educação infantil até o ensino superior.

Nesse sentido o presente artigo buscou investigar os processos e procedimentos de mediação e interação nos cursos de formação online da UFMT. A principal motivação foi pelo fato de os AVA, ao criarem condições favoráveis para que as práticas colaborativas se desenvolvam, mostrarem-se como uma das dimensões relevantes de pesquisas por se configurarem como espaços de práxis educativas. Portanto, compreender se esses Ambientes são estáveis ou não é um passo relevante para se pensar e debater propostas que consolidem e ampliem o uso deles.

Ademais, esse artigo está organizado em cinco partes, incluindo essa introdução; seguido do item sobre algumas constatações que refletem sobre os achados para essa pesquisa; posteriormente, apresenta-se o percurso metodológico com os critérios e procedimentos de coleta e análise dos dados; em seguida, reflete-se sobre usos e limitações do AVA: resultados da observação, e por fim as considerações finais.

\footnotetext{
${ }^{1}$ Laboratório de Estudos sobre as Tecnologias de Informação e Comunicação na Educação.
} 


\section{Algumas constatações}

Antes de se passar à pesquisa propriamente dita, é interessante explicitar o que foi realizado para constituir as hipóteses que fomentaram o conteúdo apresentado neste artigo. Nesse caso, foi feita uma revisão de literatura para se observar o que já havia sido construído a respeito e as possíveis lacunas em pesquisas sobre os AVA.

Os trabalhos que deram corpus à revisão de literatura e, portanto, possibilitaram a constituição de hipóteses tiveram por base as seguintes fontes: $\mathrm{O}$ Catálogo de Teses e Dissertações da Coordenadoria de Aperfeiçoamento do Pessoal de Nível Superior (CAPES); a Biblioteca Digital Brasileira de Teses e Dissertações (BDTD); o Portal de Periódicos/CAPES; e nos Grupos de Trabalho da Associação Nacional de Pesquisa em Educação (Anped), por conta da importância desta associação no cenário nacional da pesquisa em Educação. Ademais, considerou-se o intervalo de tempo dos anos de 2010 a 2018, com os seguintes descritores: "ambientes virtuais + ensino e aprendizagem"; "ambientes virtuais + formação no ensino superior"; e "ambientes virtuais + recursos educacionais". É válido ressaltar que o recorte da pesquisa realizada sobre AVA foi na área da Educação. Das buscas e seleções resultaram trinta trabalhos, os quais foram lidos integralmente para que seus objetos, objetivos, metodologias e autores mais citados fossem mapeados, compondo, assim, um cenário indicativo das tendências dos estudos. Entretanto, o levantamento completo não será apresentado aqui, já que não é objeto deste artigo.

O que se observou da análise das pesquisas foi a recorrência de uma visão bastante instrumental e tecnocêntrica no uso dos AVA, conforme já constatado por Barreto (2006) e Moraes (2016). Disso também foram obtidos resultados mais aproximados a constatações, sem que eles fossem problematizados e com debates pouco aprofundados sobre os sentidos do uso dos AVA na formação. Essas verificações se relacionam, pois, com a ideia do uso dos AVA como meras ferramentas, longe de serem considerados recursos incorporados aos processos educativos. Desse modo, os AVA seriam um apoio na distribuição de conteúdo, com uso exíguo de possibilidades que sustentassem, de fato, mediação e interação, as quais consubstanciam o diálogo necessário às práticas pedagógicas. 
Em relação às metodologias dos trabalhos selecionados, grande parte se apoiava no uso contingencial dos AVA; nenhuma tratou, efetivamente, de possibilidades do aprender e ensinar. Isso, consequentemente, dificultou a compreensão e entendimentos que indicassem a importância deles nas práticas pedagógicas/formativas. Afinal, qual é o sentido de uso dos AVA? Qual é a contribuição do uso deles no desenvolvimento curricular dos cursos? Como e de que maneira implicam os atores da formação nas dinâmicas das aprendizagens? Essas são questões em aberto para reflexões, não respondidas nos trabalhos selecionados na revisão antes mencionada.

Ao se considerarem os autores mais citados, entendendo que suas contribuições formulariam a base teórica das possíveis análises que congregassem os AVA e aprendizagens, foi possível afirmar que a maior parte deles expunha discussões, sobre as TIC e os AVA, que reconheciam diferentes dimensões do fazer pedagógico. Desse modo, os autores indicaram a complexidade de constituição de saberes sobre a temática. Pensar uma espécie de pedagogia das/com as TIC e os AVA, comprometida com valores e finalidades que pudessem ir além da técnica, estabeleceu-se como grande desafio no interior da temática aqui em debate.

No contexto da revisão então, duas hipóteses foram levantadas: a de que haveria dificuldades em se trabalhar com os AVA de ação mais extensa nas Instituições de Ensino Superior (IES), ao se convergir esse trabalho especificamente para e na EaD; e a de que os AVA, embora mais conhecidos nos últimos anos, ainda requerem decodificações e compreensões que constituam, de fato, saberes sobre eles.

Após o ajustamento do corpus da pesquisa, observou-se que a primeira hipótese prevaleceu. $\mathrm{O}$ advento da $\mathrm{EaD}$ nas IES gerou dúvidas e resistências e, no entanto, foi no escopo de se trabalhar com essa "modalidade"2 que os primeiros passos para o uso dos AVA foram realizados. Essa verificação enseja pensar e debater sobre como as IES introduzem as TIC em seu currículo e cotidiano de formação. Longe de propor perspectivas de formação que tenham adesão à cultura digital, o

\footnotetext{
${ }^{2} \mathrm{O}$ uso das aspas ao tratar da EaD como modalidade tem relação com outras publicações do Grupo de Pesquisa LêTECE. Há a compreensão de que a $\mathrm{EaD}$ não seria uma modalidade de ensino, mas apenas uma organização didático-pedagógica que considerasse, atualmente, um currículo com tecnologias.
} 
espaço das TIC/AVA se restringe, ao que parece até o momento, à EaD, consolidando uma dicotomia histórica entre o presencial e o não presencial.

Por outro lado, a problemática apontada faz refletir sobre essa "modalidade" de oferta de ensino superior. Ela é recorrentemente descontinuada, devido a depender de recursos financeiros dispostos por meio de editais, além dos espaços bastante limitados para propostas que, efetivamente, democratizem acesso, permanência e qualidade no ensino superior público em nosso país. Diante, então, das constatações e hipóteses levantadas na revisão é que se propôs a pesquisa, cujas partes de seus resultados são refletidos aqui nesse texto.

\section{Percursos metodológicos}

Diante das possibilidades e recursos que os AVA disponibilizam e com base na revisão realizada citada no item anterior, o objeto da pesquisa foi caracterizado como processos e procedimentos de interação e mediação nos AVA dos cursos online da UFMT. O objetivo geral foi, então, o de analisar o uso dos AVA nos cursos online, no sentido de se reconhecerem neles, ou não, processos e procedimentos de interação e de mediação, que tiveram por base a identificação desses elementos que se constituíam nos AVA/Moodle ${ }^{3}$ utilizados na instituição, bem como as práticas colaborativas que se desenvolviam por meio deles, para refletir como esses processos de mediação e de interação podem ser identificados nos cursos de formação online da instituição. A intenção com isso é constituir saberes sobre a relevância dos AVA como espaços de formação, devido a sustentarem "lugares" de outras e novas apropriações das práticas pedagógicas no contexto da cultura digital, isso porque eles manifestam uma formação com uso mais intenso de tecnologias.

A abordagem trabalhada na pesquisa foi a qualitativa (DENZIN; LINCOLN, 2006), com a metodologia da observação participante, que é "considerada processo pelo qual a interação da teoria com a prática concorre para a transformação ou implementação do meio pesquisado” (QUEIROZ et al., 2017, p. 278). Tendo em

\footnotetext{
${ }^{3}$ Acrônimo de "Modular Object-Oriented Dynamic Learning Environment", um software livre, de apoio à aprendizagem, executado num ambiente virtual.
} 
conta essa perspectiva, o pesquisador assumiria, então, o papel de integrante do grupo, possibilitando o trabalho de uma visão mais ampla e detalhada da realidade.

A observação toma parte no meio aonde as pessoas se envolvem. Por um lado, esta metodologia proporciona uma aproximação ao quotidiano dos indivíduos e das suas representações sociais, da sua dimensão histórica, sócio-cultural, dos seus processos. Por outro lado, permite-lhe intervir nesse mesmo quotidiano, e nele trabalhar ao nível das representações sociais, e propiciar a emergência de novas necessidades para os indivíduos que ali desenvolvem as suas atividades (MÓNICO et al., 2017, p. 727).

A observação participante, nesse caso, ocorreu efetivamente nos AVA, sendo este espaço o lócus da investigação, em três cursos online detalhados adiante. A participação do pesquisador se deu no decorrer do desenvolvimento do trabalho didático-pedagógico e sua inserção junto à equipe multiprofissional, formada por professores e alunos, ocorreu de acordo com as dúvidas, dificuldades e questionamentos que surgiram no tempo da observação participante.

A maior parte dos dados coletados teve por base os relatórios de atividades das disciplinas disponíveis nos AVA. Esses relatórios estão disponíveis no Moodle e contêm informações relacionadas ao acesso e utilização de recursos de comunicação, os quais possibilitam os processos e procedimentos de mediação e de interação. Para Silva (2011, p. 20), "é inegável a importância do uso de relatórios no acompanhamento da dinâmica do processo ensino aprendizagem, uma vez que estes contribuem de modo significativo para a tomada de decisão no momento da avaliação da aprendizagem".

Para selecionar os cursos de graduação a serem investigados na pesquisa, buscou-se acesso a sua oferta online na UFMT. Como um dos critérios de escolha, elegeram-se os cursos de graduação que já tinham desenvolvido 30\% ou mais de seu currículo, considerando maior estabilidade de alunos regulares com matrícula ativa. Com esse critério, foram selecionados três cursos de graduação na modalidade a distância e com oferta online, cujas atividades foram iniciadas no segundo semestre de 2017: Bacharelado em Administração Pública; Licenciatura em Ciências Naturais e Matemática; e Licenciatura em Pedagogia.

Por questões logísticas, seria impossível observar todas as disciplinas já concluídas e as que estavam em andamento; surge, então, a necessidade de se elegerem algumas delas para a pesquisa. Para a seleção dessas disciplinas, foi distribuído um 
questionário online aos alunos matriculados nos três cursos de graduação, com o objetivo de que eles indicassem as "matérias" que considerassem como aquelas em que processos de interação e mediação foram consolidados. Nesse questionário, os alunos responderam a cinco questões: gênero; idade; o curso em que estava matriculado; qual(is) disciplina(s) cursada(s) identificavam como aquela(s) em que os processos de interação e mediação ocorreram intensamente; e os fatores que contribuíram para isto.

Os questionários foram enviados por meio do e-mail dos AVA, com aprovação das coordenações dos cursos e da coordenação da Universidade Aberta do Brasil (UAB) na UFMT ${ }^{4}$. Os e-mails foram enviados para 765 alunos, sendo eles: 203 do curso de Licenciatura em Pedagogia; 328 do curso de Licenciatura em Ciências Naturais e Matemática; e 234 do curso de Bacharelado em Administração Pública. Do total, 124 alunos responderam ao questionário. Desses, 42 eram do curso de Bacharelado em Administração Pública, 60 do curso de Licenciatura em Ciências Naturais e Matemática, e 22 do curso de Licenciatura em Pedagogia. Apesar do número de respondentes ser baixo, comparado ao total de matriculados, houve indicação de um número bastante razoável de disciplinas consideradas pelos alunos como aquelas com intensos processos e procedimentos de mediação e de interação. Esse número totalizou 19 indicações para cada um dos cursos. Frente a isso, foram trabalhados mais dois critérios: o de selecionar as disciplinas que apresentavam três ou mais indicações pelos alunos e o de escolher as que estavam finalizadas nos AVA, de modo a se observar todo um ciclo de trabalho/formação.

O resultado dessa observação participante é apresentado a seguir.

\section{Usos e limitações do AVA: resultados}

Conforme antes mencionado, os passos iniciais da pesquisa são recentes, de modo que o exposto a seguir é parte dos resultados vinculados à primeira fase do trabalho. A título de informação, é importante destacar que foi realizado o download dos relatórios de atividades de todas as disciplinas pré-selecionadas e indicadas pelos alunos no questionário. Os resultados dividem-se em: 22 disciplinas, 15 polos e 37

\footnotetext{
${ }^{4}$ Aprovado pelo Comitê de Ética em Pesquisa (CEP), com número CAAE 07819518.0.0000.5690. 
turmas, totalizando 277 relatórios de atividades, que foram observados individualmente, levando em consideração os que dispunham de maior participação em recursos de comunicação disponíveis nos AVA/disciplinas. Com base na observação desses relatórios, foram selecionadas então três disciplinas de cada curso, sobretudo aquelas que apontavam maior índice de participação entre alunos, professores e tutores.

Para melhor compreensão do que estamos falando, o Quadro 1 detalha os cursos, os polos/turmas, as disciplinas, os recursos de comunicação utilizados, assim como a carga horária e o período de realização dessas disciplinas no AVA.

Quadro 1- Disciplinas analisadas após observação dos relatórios de atividades

\begin{tabular}{|c|c|c|c|c|c|}
\hline Curso & $\begin{array}{l}\text { Polo/ } \\
\text { Turma }\end{array}$ & Disciplina & $\begin{array}{l}\text { Recurso } \\
\text { Utilizado }\end{array}$ & $\begin{array}{l}\text { Carga } \\
\text { Horária }\end{array}$ & $\begin{array}{l}\text { Realizaçã } \\
\text { o }\end{array}$ \\
\hline \multirow{3}{*}{$\begin{array}{l}\text { Bacharelado } \\
\text { em } \\
\text { Administração } \\
\text { Pública } \\
\text { modalidade a } \\
\text { Distância }\end{array}$} & $\begin{array}{l}\text { Cuiabá } \\
\text { (Turma 2) }\end{array}$ & $\begin{array}{l}\text { Estatística Aplicada a } \\
\text { Administração }\end{array}$ & $\begin{array}{l}\text { Atividade } \\
\text { Fórum }\end{array}$ & $60 \mathrm{~h}$ & $\begin{array}{l}08 / 12 / 18 \mathrm{a} \\
01 / 02 / 19\end{array}$ \\
\hline & $\begin{array}{r}\text { Cuiabá } \\
\text { (Turma 1) }\end{array}$ & $\begin{array}{l}\text { Seminário em Gestão de } \\
\text { Escola Pública }\end{array}$ & $\begin{array}{l}\text { Atividade } \\
\text { Fórum }\end{array}$ & $30 \mathrm{~h}$ & $\begin{array}{l}21 / 10 / 17 \text { a } \\
24 / 03 / 18\end{array}$ \\
\hline & $\begin{array}{r}\text { Cuiabá } \\
\text { (Turma 4) }\end{array}$ & Seminário Integrador & $\begin{array}{l}\text { Atividade } \\
\text { Fórum }\end{array}$ & $30 \mathrm{~h}$ & $\begin{array}{l}10 / 06 / 17 \text { a } \\
07 / 10 / 17\end{array}$ \\
\hline \multirow{3}{*}{$\begin{array}{l}\text { Licenciatura } \\
\text { em Ciências } \\
\text { Naturais e } \\
\text { Matemática } \\
\text { modalidade a } \\
\text { Distância }\end{array}$} & $\begin{array}{l}\text { Canarana } \\
\text { (Turma 2) }\end{array}$ & $\begin{array}{l}\text { A Epistemologia de } \\
\text { Toulmin e Maturana e } \\
\text { suas Implicações para o } \\
\text { Ensino de Ciências }\end{array}$ & $\begin{array}{l}\text { Atividade } \\
\text { Fórum }\end{array}$ & $30 \mathrm{~h}$ & $\begin{array}{l}13 / 04 / 18 \mathrm{a} \\
10 / 06 / 18\end{array}$ \\
\hline & $\begin{array}{r}\text { Cuiabá } \\
\text { (Turma 3) }\end{array}$ & A origem do Universo & $\begin{array}{l}\text { Atividade } \\
\text { Fórum }\end{array}$ & $60 \mathrm{~h}$ & $\begin{array}{l}20 / 10 / 17 a \\
17 / 12 / 17\end{array}$ \\
\hline & $\begin{array}{l}\text { Guarantã do } \\
\text { Norte } \\
\text { (Turma 2) }\end{array}$ & $\begin{array}{l}\text { Ensino de matemática I: } \\
\text { sistema de numeração e } \\
\text { operações }\end{array}$ & $\begin{array}{l}\text { Atividade } \\
\text { Fórum }\end{array}$ & $60 \mathrm{~h}$ & $\begin{array}{l}09 / 02 / 18 \text { a } \\
08 / 04 / 18\end{array}$ \\
\hline \multirow[t]{3}{*}{$\begin{array}{l}\text { Licenciatura } \\
\text { em Pedagogia } \\
\text { modalidade a } \\
\text { Distância }\end{array}$} & $\begin{array}{l}\text { Água Boa } \\
\text { (Turma 1) }\end{array}$ & $\begin{array}{l}\text { Múltiplas Linguagens } \\
\text { Literatura Infantil }\end{array}$ & $\begin{array}{l}\text { Biblioteca } \\
\text { Online } \\
\text { Fórum } \\
\text { Glossário }\end{array}$ & $60 \mathrm{~h}$ & $\begin{array}{l}08 / 04 / 19 a \\
05 / 05 / 19\end{array}$ \\
\hline & $\begin{array}{l}\text { Canarana } \\
\text { (Turma 3) }\end{array}$ & Psicologia I & $\begin{array}{l}\text { Atividade } \\
\text { Fórum }\end{array}$ & $60 \mathrm{~h}$ & $\begin{array}{l}10 / 07 / 17 \text { a } \\
30 / 07 / 17\end{array}$ \\
\hline & $\begin{array}{l}\text { Juara } \\
\text { (Turma 3) }\end{array}$ & $\begin{array}{l}\text { Seminário Integrador } \\
\text { Memórias de Estudantes }\end{array}$ & $\begin{array}{l}\text { Atividade } \\
\text { Chat } \\
\text { Fórum }\end{array}$ & $100 \mathrm{~h}$ & $\begin{array}{l}12 / 06 / 17 \text { a } \\
23 / 09 / 17\end{array}$ \\
\hline
\end{tabular}

Fonte: Dados coletados e organizados pelas autoras, 2020.

Após essa seleção, foi realizada a observação em cada uma dessas disciplinas, em seus respectivos polos e turmas, identificando os processos de participação com o uso dos recursos de comunicação disponíveis nos AVA. Para tanto, foram 
considerados quatro elementos: a) Quais os recursos de comunicação utilizados pelos alunos, professores e tutores; b) Como se estabeleceu a comunicação entre eles; c) Quais atividades deram base às interações; d) Como essas atividades estavam organizadas.

Conforme disposto ao CEP da UFMT, a descrição do que fora observado no AVA foi sistematizada da seguinte forma: o curso de Bacharelado em Administração Pública na modalidade EaD, doravante AP, teve as disciplinas observadas no Moodle chamadas de APD1, APD2 e APD3; no curso de Licenciatura em Ciências Naturais e Matemática na modalidade $\mathrm{EaD}$, as denominações das disciplinas foram de CNMD1, CNMD2 e CNMD3; e com relação ao curso de Licenciatura em Pedagogia na modalidade EaD, foram escolhidas as siglas LPD1, LPD2 e LPD3.

Considerando o exposto acima, foi possível observar que em APD2 e APD3 o Fórum foi, basicamente, o recurso de comunicação utilizado. Esse recurso é uma atividade de comunicação assíncrona e com baixas possibilidades de trocas, caso não haja acompanhamento efetivo dos sujeitos da formação. Na primeira disciplina, o Fórum foi realizado pelo professor, o qual solicitou que os alunos participassem de uma discussão sobre determinado assunto. A atividade que deu base a alguma interação foi o feedback do tutor para cada uma das participações dos alunos. $\mathrm{Na}$ segunda disciplina, também com o Fórum, a atividade que mais fomentou participação foi aquela em que o professor solicitou a apresentação da turma, com destaque à justificativa da escolha do curso. Por fim, a atividade que mais possibilitou interação foi a conversação espontânea entre alunos e o tutor com perguntas, respostas e comentários a respeito das postagens do Fórum.

A interação entre professores e alunos na educação a distância é relevante para a manutenção do interesse dos alunos. O fórum por si mesmo não promove a interação. Essa só pode ser efetivada a partir da intencionalidade dos professores e alunos associada a um objetivo maior que é o alcance do conhecimento (BATISTA; GOBARA, 2007, p. 3).

Em relação ao recurso Atividade, nas disciplinas antes citadas, houve um mesmo procedimento de organização: os professores trabalharam, com pequenos vídeos, as orientações sobre a realização de determinadas tarefas, cujas respostas seriam enviadas na forma de arquivo. As poucas interações relacionadas a isso foram os "Comentários de feedback" e “Arquivos de feedback". Nos primeiros, o tutor 
enviava comentários sobre as atividades, parabenizando os que as realizaram com sucesso ou sugerindo alterações e/ou melhorias a outros. No segundo, o tutor reenviava o próprio arquivo que o aluno postara, com correções, sugestões e orientações.

Na terceira disciplina, APD1, o recurso de comunicação utilizado também foi o Fórum. Na observação, no entanto, foi identificado que era um fórum de suporte técnico, no qual se reportavam problemas técnicos relacionados ao uso dos AVA. Como esse Fórum não tinha relação com os recursos de comunicação voltados à disciplina propriamente, optou-se por sua exclusão. Disto resultou-se a necessidade de que fossem observados, nas demais disciplinas, o que seria o "Fórum". É interessante apontar que o Fórum relacionado ao suporte técnico era bem concorrido.

Nas disciplinas CNMD1, os recursos de comunicação utilizados foram: Fórum de Dúvidas; Fórum de Discussão; e Atividade. Esses recursos estabeleceram uma comunicação assíncrona entre aluno e tutor. O Fórum de Dúvidas fora organizado pelo professor com o objetivo de que os alunos tirassem dúvidas e postassem sugestões a respeito da disciplina. Nesse Fórum, o professor fez postagens com recomendações de textos e vídeos; no entanto, não houve nenhuma participação dos alunos. A organização do Fórum de Discussão esteve relacionada ao material disponibilizado para leitura; contudo, os alunos participavam com respostas lineares, sem que houvesse interações entre eles, o tutor e o professor. Já com o recurso Atividade, a organização se deu em etapas, considerando os diferentes momentos de desenvolvimento da disciplina, com os alunos respondendo online. Nesse caso, as interações tinham base nos comentários do tutor, que apreciava algumas partes do que fora solicitado/respondido ao fazer comentários com feedback ou orientações de possíveis melhorias a serem feitas.

Nas disciplinas CNMD2 e CNMD3, da mesma maneira estavam presentes recursos de comunicação do Fórum de Dúvida e Atividade, com comunicação assíncrona, como já observado anteriormente. A organização do Fórum de Dúvida pelo professor se deu pela disponibilização de vídeos e textos, deixando espaço aberto para dúvidas, sugestões e interações entre alunos, tutores e professores. Mais uma vez, a interação foi com o tutor, que respondeu as dúvidas dos alunos com questionamentos sobre o conteúdo em estudo. Com as Atividades, também se deu o 
envio de textos online e de arquivos. O que deu base à interação foram os comentários que ocorriam apenas com os alunos que tiveram de rever suas respostas nas tarefas solicitadas.

$\mathrm{Na}$ disciplina LPD1, os recursos de comunicação observados foram: Fórum de Discussão; Biblioteca Online; e Atividade. Todos esses recursos eram utilizados por meio de comunicação assíncrona. Foi trabalhado aqui um "Fórum Simples", organizado pelo docente da disciplina, o qual apresentou um vídeo explicativo sobre o assunto que seria debatido. Neste caso, houve mediação do professor nas discussões e participação de cada um dos alunos, com questionamentos e proposição de reflexões e sugestões de livros, links e vídeos. A participação do tutor e dos alunos foi bastante ativa, com debates e discussões coletivas.

O recurso da Biblioteca Online também foi organizado pelo docente e desenvolvido em grupo de alunos, que seguiram um roteiro disponível para download. As interações ocorreram com frequência, e nelas o professor mediou, constantemente, os debates, bem como os passos a serem desenvolvidos na realização dessa tarefa. Os trabalhos dos alunos foram acompanhados e avaliados tanto pelo docente quanto pelo tutor, de modo que as sugestões e indicações de outros materiais estiveram vinculadas ao aprofundamento de leituras e compreensão da temática em estudo. Todo material produzido pelo conjunto dos alunos foi compartilhado na Biblioteca Online, permitindo, assim, o acesso de todos à produção coletiva.

No contexto dessa disciplina, de intensa mediação e interação entre os sujeitos partícipes da formação, é de extrema relevância a ideia de Thompson (2008). Para ele, nas sociedades interconectadas as experiências humanas seriam cada vez mais mediadas, o que constitui vivências cada vez mais (re)contextualizadas. Isso em razão do que ele denomina como deslocamento espaço-tempo, cujo movimento de aproximar realidades e contextos (re)configura a ação humana, devido a extrapolar e transcender estruturas tradicionais do pensamento político e moral (ALONSO, 2017). Corroborando com essa discussão, convém ressaltar que:

A participação e interação visam colocar o sujeito da aprendizagem em uma posição ativa no desenvolvimento do processo educacional e face à elaboração do conhecimento. Assim, o conhecimento será entendido como uma transformação oriunda da convivência e dos espaços compartilhados, nos quais a participação e interação entre os sujeitos resultam em um processo de transformação de relações (SILVA; MACIEL; ALONSO, 2013, p. 15). 
E foi o que ocorreu nessa disciplina com intensos momentos de mediação e interação entre os alunos, professores e tutores. No recurso Atividade, do mesmo modo, as interações tiveram por base o feedback do tutor nos trabalhos postados pelos alunos. Esse tutor destacou itens relacionados ao conteúdo enviado, com identificação de possíveis melhorias a serem realizadas para reenvio posterior do trabalho. Da mesma maneira, o professor participou ativamente ao indicar materiais que apoiavam melhor compreensão do assunto abordado.

No que tange aos feedbacks do tutor sobre os envios dos arquivos no recurso Atividade, é importante destacar a compreensão de interação apenas como ação e reação (BERLO, 1991). "Por adotar-se o paradigma ação-reação passa-se à visualização do processo de uma forma linear e do ponto de vista da fonte (onde existe apenas a emissão e o feedback, onde esse último teria apenas a função de comprovar a 'eficácia' da mensagem)" (BERLO, 1991, p. 117). Ao falar sobre isso, Silva (2011, p. 23) complementa dizendo que compreender a interação de "forma limitante como ação-reação seria o mesmo que desconsiderar o processo, admitindo um começo, meio e fim de forma linear, sequencial e interdependente, desconsiderando a dinâmica comunicacional e a inversão dos atores comunicacionais".

A disciplina LPD2 contou com os recursos de comunicação Fórum, Wiki e Diário Online. Nos últimos casos, como Wiki e Diário Online são recursos comunicacionais diferentes, os alunos optariam por um ou outro, e de toda maneira eles também são recursos assíncronos, cujas atividades foram desenvolvidas pelo tutor e alunos. No decorrer da disciplina, foram realizados também seis Fóruns: de Dúvidas; Apresentação; Psicologia da Aprendizagem; Psicologia da Personalidade; Avaliando Minha Caminhada de Estudo; e de Confraternização Virtual.

O Fórum de Dúvidas foi dedicado à interação entre alunos e professor sobre dúvidas gerais da disciplina, seguindo aberto todo o tempo em que ela aconteceu. No Fórum de Apresentação, os alunos discorriam sobre determinado assunto, debatendo com os demais por meio de diálogo estabelecido por argumentos, réplicas e tréplicas. No Fórum Psicologia da Aprendizagem, foi solicitado aos alunos que entrevistassem três professores em exercício, para que eles definissem o que seria aprendizagem. Com base nas respostas obtidas, foi pedido que fizessem, então, uma correlação delas com 
as teorias da aprendizagem em estudo, compartilhando as reflexões com a turma de modo a se constituir também argumentos, réplicas e tréplicas. O Fórum Psicologia da Personalidade foi realizado por duplas de alunos, e o trabalho foi a escolha de filmes que, uma vez vistos, fossem relacionados com as teorias da Personalidade; em seguida, do mesmo modo que nos fóruns anteriores, argumentos deveriam ser propostos ao debate. Já no Fórum Avaliando Minha Caminhada de Estudo, foi solicitada a contribuição dos alunos para que construíssem quatro questões de avaliação sobre os estudos; nesse caso, porém, não ocorreu a participação de nenhum dos alunos. Por fim, o Fórum Confraternização Virtual foi dedicado ao compartilhamento de experiências de aprendizagem na disciplina pelos alunos, para que então postassem mensagens de despedida aos colegas, tutor e professor. Importante observar que a interação no caso se deu somente entre os alunos.

Pelo que foi observado, a estratégia de se proporem argumentos, com réplicas e tréplicas, contribui muito para as interações, embora isso tenha se restringido aos alunos e tutor.

Com os recursos de comunicação Wiki ou Diário Online, a depender de qual fosse escolhido, foi solicitado que os alunos elaborassem fichamentos, em formato digital, das leituras realizadas sobre parte dos estudos do material impresso/fascículo da disciplina e sobre um texto disponibilizado para download. Não houve, no entanto, participação dos alunos nessas atividades.

Na LPD3, foram utilizados recursos de comunicação como Fórum e Chat. O Fórum, intitulado "Relembrando Memórias de Estudantes", foi organizado para se compartilharem dúvidas, contribuições e trechos da escrita das memórias de estudante, com o tutor e os alunos da turma. O que deu base às interações foram os feedbacks do tutor em cada uma das postagens dos alunos. Já o Chat, intitulado "Memórias de Estudante", foi caracterizado como um momento de diálogo síncrono entre os alunos e tutor. Quando o Chat foi acessado, percebeu-se que os alunos entraram em dias e horários diferenciados, cada um deles criando uma sessão individual, finalizada em seguida, sem que fossem observados diálogos uns com os outros e sem a participação do tutor e do professor.

Refletindo sobre esse processo de mediação e de interação entre os sujeitos, algumas indagações são necessárias: somente a presença do tutor é suficiente para 
dizer que de fato há aprendizagem? Que há mediação? Que há interação? Ao falarem sobre o assunto, Palloff e Pratt (2004, p. 141) afirmam que "incentivar um alto nível de interação é papel fundamental do professor. Na verdade, talvez seja a sua tarefa mais importante no ambiente de aprendizagem on-line”. O professor, portanto, é um mediador entre aquele que aprende (sujeito) e o mundo, apoiando-o a interagir com os outros e consigo mesmo (VIGOTSKI, 2007).

A observação, bem como a possibilidade de participar junto aos grupos no processo de formação, foi de importância crucial no sentido de, primeiramente, perceber-se como se constituem os cotidianos de uso dos AVA. Em segundo lugar, o pouco esforço, em relação a se superarem modelos educativos cristalizados em que os professores definem os encaminhamentos, de alguma maneira impõe reflexões que, ao final, contradizem discursos sobre o que seria um trabalho coletivo e colaborativo.

Já faz algum tempo que o alerta sobre o sentido do uso dos AVA disparava, como afirmavam Costa e Franco (2005):

O problema das interações representa essencialmente um contingente de ordem pedagógica (Dillenbourg, 2003). Estabelecer um ambiente colaborativo de aprendizagem não está limitado por questões técnicas, já que a utilização do correio eletrônico e dos chats, por exemplo, não apresenta maiores limitações. O desafio consiste em tornar essas comunicações em algo construtivo para a aprendizagem. (COSTA; FRANCO, 2005, p. 4).

O olhar sobre os AVA remete sempre ao debate sobre aquilo que precede seu uso propriamente dito: afinal, qual é a compreensão que se tem sobre o artefato? Quais as intenções pedagógicas pretendidas? Quais objetivos educacionais/de formação estão presentes em seu uso? Como e de que maneira as instituições de ensino, no caso superior, pensam/propõem o uso mais intenso das TIC em seus processos formativos? Esses e outros questionamentos continuam em aberto para reflexão, pois não há pretensão de se pensar o artefato AVA como algo neutro ou de se acusarem professores e tutores. Também não há intenções de se acusar a falta de autonomia dos alunos naquilo que parece ser, considerando a pesquisa em tela, pouco ou nenhum esforço a respeito de fomentar e constituir processos/procedimentos de acompanhamento efetivos para as aprendizagens.

O fetiche AVA paira sobre nossas cabeças como uma panaceia. Bastaria incluílo no dia a dia da formação para que grande parte dos problemas pedagógicos, 
sobretudo os relacionados aos processos de constituição dos significados educativos que se pretendem para e nessa formação, fossem, como um passe de mágica, solucionados pelas possibilidades da comunicação em tempo real e da disponibilidade da informação em diferentes e lindas mídias.

No entanto, a pesquisa indica que, apesar das possibilidades anteriormente postas, faz-se necessária uma discussão sobre políticas públicas e institucionais, sobre o trabalho docente e do tutor e, no caso da EaD, sobre o "lugar" do aluno no contexto da cultura digital e da sociedade conectada. Desse modo, converge-se o uso significativo das TIC/AVA. Ressignificar os processos educativos em seus currículos, modos e maneiras de se trabalhar o escolar - entendido aqui como espaço da educação formal - e o pedagógico, sem ter por horizonte a constituição de uma cultura escolar que faça ruir as estruturas do que já está cristalizado, é matar no nascedouro algo que traz em si um devir. É impossível se trabalhar com o novo diante das restrições, sobretudo econômicas, que se colocam às instituições de ensino no momento. Sem experimentações, sem projetos que tenham por finalidade compreender a inserção e os significados que as crianças e jovens empreendem sobre os novos contextos comunicacionais, é difícil a aproximação com os novos saberes que emergem a partir disso. Do mesmo modo, trabalhar com a EaD, considerando o potencial de democratização de acesso ao ensino superior que ela traz, sem ponderar sobre processos formativos que assegurem qualidade nesse trabalho é deixar de lado um potencial que certamente poderia vivificar práticas pedagógicas inovadoras, quando se pensa nas possibilidades de virtualização dos processos educativos.

\section{Considerações finais}

É válido ressaltar que a pesquisa e que as análises mais aprofundadas sobre o objeto em investigação continuam. Nesse sentido, destaca-se também a necessidade de outras instituições de ensino superior fomentarem estudos que possam congregar os diversos modos pelos quais o trabalho com as TIC/AVA vem se realizando.

A pesquisa não se trata de acusar ou enaltecer essa ou aquela experiência, mas sim de se ter como objetivo encontrar respostas para determinadas questões de maneira a produzir novos conhecimentos, visando a superação do que já é conhecido. 
Sendo assim, as pesquisas que têm por objeto a mediação e a interação como elementos intrínsecos à aprendizagem, e a partir disso o uso das TIC/AVA, configuram-se, no contexto da cultura digital, como potencializadoras para se pensar a instituição escolar, em seus vários níveis.

As práticas pedagógicas que são geradas quando a escola perde protagonismo histórico na disseminação de saberes/conhecimentos, diluindo as fronteiras nesse domínio, estão em constituição. Nega-se o anterior sem que ainda se tenha o novo, como em todo processo histórico. Trabalhar os limites institucionais, considerando os sujeitos que habitam os universos educacionais, sejam eles alunos, professores, gestores e entre outros, além do tutor no caso da EaD, significa compreender como o uso das TIC/AVA tem se projetado no trabalho pedagógico.

Com isso, entendem-se os contextos e entornos em que essas tecnologias e ambientes se realizam, e é esse o desafio posto aos educadores hoje. Tudo isso é o convite que se faz para que pesquisas que têm por base tal perspectiva possam ser trabalhadas, contribuindo, assim, para a concretização do debate, da democratização e da qualidade na formação num contexto de intenso uso das TIC.

\section{Referências}

ALONSO, K.; SILVA, D. G. A Educação a Distância e a Formação On-line: o Cenário das Pesquisas, Metodologias e Tendências. Educação \& Sociedade, v. 139, n. 143, p. 499-514, abr./jun. 2018.

ALONSO, K. Cultura Digital e formação: entre um devir e realidades pungentes. In: CERNY, R. Z.; RAMOS, E. M. F (Org.). Formação de Educadores na Cultura Digital: a Construção Coletiva de uma proposta. Florianópolis: UFSC/CED/NUP, 2017.

BARRETO, R. G. Educação e tecnologia (1996-2002). Brasília: MEC/Inep, 2006.

BATISTA, E. M.; GOBARA, S. T. O fórum online e a interação em um curso a distância. Revista RENOTE - Novas Tecnologias na Educação, v. 5, n. 1, 2007.

BERLO, K. D. O Processo da Comunicação: Introdução à Teoria e à Prática. 7. ed. São Paulo: Martins Fontes, 1991.

COSTA, L. A. C. da; FRANCO, S. R. K. Ambientes virtuais de aprendizagem e suas possibilidades construtivistas. CINTED-UFRGS, Porto Alegre, v. 3, n. 1, p. 1-10, mai. 2005.

DENZIN, N. K.; LINCOLN, Y. S. O Planejamento da Pesquisa Qualitativa: teorias e abordagens. Trad. Sandra Regina Netz. 2. ed. Porto Alegre: Artmed, 2006. 
KERCKHOVE, D. de. A pele da cultura: investigando a nova realidade eletrônica. São Paulo: Annablume, 2009.

MAIESKI, A.; SILVA. D. G. Apropriações e Sentido na Formação On-line: Conceitos e Práticas em questão. Educação \& Sociedade, Campinas, v. 42, p. 1-15, abr. 2021.

MÓNICO, L. S.; ALFERES, V. R.; CASTRO, P. A.; PARREIRA, P. M. A Observação Participante enquanto metodologia de investigação qualitativa. Atas - Investigação Qualitativa em Ciências Sociais, v. 3, 2017.

MORAES, M. G. Pesquisas sobre educação e tecnologias: questões emergentes e configuração de uma temática. Orientadora: Joana Peixoto. $161 \mathrm{f}$. Tese (Doutorado em Educação) — Faculdade de Educação, Pontifícia Universidade Católica, Goiânia, 2016.

PALLOFF, R. M.; PRAT', K. O aluno virtual: um guia para trabalhar com estudantes on-line. Porto Alegre: Artmed, 2004.

QUEIROZ, D. T.; VALL, J.; SOUZA, Â. M. A.; VIEIRA, N. F. Observação Participante na Pesquisa Qualitativa: Conceitos e Aplicações na área da Saúde. Revista Enfermagem UERJ, Rio de Janeiro, p. 276-283, abr./jun. 2007.

SILVA, D. G. da. Trajetórias de formação em ambientes virtuais: entendimentos e percepções da mediação, interação e interatividade. Orientadora: Kátia Morosov Alonso. 2015. 296 f. Tese (Doutorado em Educação) - Faculdade de Educação, Universidade Federal de Mato Grosso, Cuiabá, 2015.

SILVA, D. G. da. Análise sobre o uso dos relatórios de atividades do Moodle no acompanbamento do processo de aprendizagem de alunos em curso de graduação. Orientadora: Kátia Morosov Alonso. 2011. 137 f. Dissertação (Mestrado em Educação) — Universidade Federal de Mato Grosso, Cuiabá, 2011.

SILVA, D. G; MACIEL, C; ALONSO, K. M. Relatório das atividades do Moodle: perspectivas sobre a participação e interação em ambientes virtuais de aprendizagem. In: ALBUQUERQUE, D. C. S. H.; PEREIRA, V. C. (Orgs.). Construindo a EaD: primeiros passos. Cuiabá, MT: IFMT, 2013.

THOMPSON, J. B. A Mídia e a Modernidade: Uma teoria social da mídia. 9. ed. Petrópolis: Vozes, 2008.

VIGOSTSKI, L. S. A formação Social da Mente. Org. Michael Cole. 7. ed. São Paulo: Martins Fontes, 2007. 